\title{
Analise e desenvolvimento de um software para o gerenciamento do demonstrativo de fluxo de caixa da merenda escolar de uma escola pública municipal da Cidade de
}

\section{Amorinópolis - Goiás}

\author{
Analysis and development of a software for the management of the cash flow statement for school \\ meal in a municipal public school in the Amorinópolis City- Goiás
}

Análisis y desarrollo de un software para la gestión del estado de flujo de caja para el merenda escolar en un colegio público municipal dela Ciudad de Amorinópolis - Goiás

Recebido: 04/02/2021 | Revisado: 07/02/2021 | Aceito: 11/02/2021 | Publicado: 19/02/2021

\author{
Maíra Cristina dos Reis \\ ORCID: https://orcid.org/0000-0001-5889-5677 \\ Instituto Federal de Educação, Ciência e Tecnologia Goiano, Brasil \\ E-mail: mairacreis@hotmail.com \\ Luciana Recart Cardoso \\ ORCID: https://orcid.org/0000-0001-7987-2722 \\ Instituto Federal de Educação, Ciência e Tecnologia Goiano, Brasil \\ E-mail: luciana.cardoso@ifgoiano.edu.br
}

\begin{abstract}
Resumo
A alimentação escolar, mais conhecida como "merenda escolar" é um direito dos alunos de escolas da rede públicas. O objetivo dessa alimentação é contribuir para o desenvolvimento integral dos alunos e consequentemente colaborar com seu aprendizado. Os recursos destinados à merenda escolar são repassados mensalmente, baseados no valor percapita, é no censo escolar, assim os governos estadual e federal ficam responsáveis pelo repasse das verbas as escolas públicas. Com o recebimento de recursos é determinado que as escolas prestem contas anualmente sobre os valores utilizados. No mercado atual a poucos softwares que auxiliem na prestação de contas relacionada a merenda, além de não serem gratuitos. Diante disso, o presente estudo tem por objetivo descrever as atividades inerentes a analise e modelagem de um software na plataforma Web com o intuito de gerenciar os recursos destinados à merenda escolar. Metodologicamente, o estudo classifica-se como sendo de natureza qualitativa, empregada através de entrevistas e pesquisa bibliográfica. Com o desenvolvimento do software espera-se contribuir para o aprimoramento do controle dos dados relacionados à merenda escolar, visando aperfeiçoar o aproveitamento dos recursos destinados através do planejamento informatizado de cardápios e geração de relatórios.
\end{abstract}

Palavras-chave: Merenda escolar; Sistema Web; Fluxo de caixa.

\begin{abstract}
School alimentation, better known as "school meals" are a right of students in public schools. The purpose of this food is to contribute to the integral development of students and consequently collaborate with their learning. The resources destined for school meals are transferred monthly, based on the per capita amount, it is in the school census, so the state and federal governments are responsible for the transfer of funds to public schools. With the receipt of funds, it is determined that schools report annually on the amounts used. In the current market there are little software that help with accountability related to meals, besides not being free. Therefore, this study aims to describe the activities inherent to the analysis and modeling of software on the Web platform in order to manage the resources destined for school meals. Methodologically, the study is classified as being of a qualitative nature, used through interviews and bibliographic research. With the development of the software, it is expected to contribute to the improvement of the control of data related to school meals, aiming to improve the use of resources destined through the computerized planning of menus and the generation of reports.
\end{abstract}

Keywords: School meals; Web system; Cash flow.

\section{Resumen}

La alimentación escolar, más conocidas como "comidas escolares", son un derecho de los estudiantes en las escuelas públicas. El propósito de este alimento es contribuir al desarrollo integral de los estudiantes y en consecuencia colaborar con su aprendizaje. Los recursos destinados a las comidas escolares se transfieren mensualmente, con base en el monto per cápita, está en el censo escolar, por lo que los gobiernos estatal y federal son responsables de la transferencia de fondos a las escuelas públicas. Con la recepción de los fondos, se determina que las escuelas 
informan anualmente sobre las cantidades utilizadas. En el mercado actual existen pocos software que ayuden con la rendición de cuentas relacionada con las comidas, además de no ser gratuitos. Por tanto, este estudio tiene como objetivo describir las actividades inherentes al análisis y modelado de software en la plataforma Web con el fin de gestionar los recursos destinados a la alimentación escolar. Metodológicamente, el estudio se clasifica como de carácter cualitativo, utilizado a través de entrevistas e investigación bibliográfica. Con el desarrollo del software se espera contribuir a la mejora del control de los datos relacionados con las comidas escolares, con el objetivo de mejorar el uso de los recursos destinados a través de la planificación informatizada de menús y la generación de informes.

Palabras clave: Comidas escolares; Sistema Web; Flujo de caja.

\section{Introdução}

A merenda escolar é uma refeição oferecida aos alunos de escolas da rede pública custeada pelo Governo Federal. Teve seu início em meados de 1940, após o governo federal observar que a ação de destinar verbas para a complementação alimentar dos estudantes resultava na sua permanência nas escolas e na redução da desnutrição infantil. (Ramos et al., 2020). Segundo Chaves e Brito (2006) em 1955, o então presidente do Brasil, Juscelino Kubitschek de Oliveira, assinou o decreto que originou a Campanha da Merenda Escolar (CME). Posteriormente, em 1979, o nome da campanha foi alterado para Programa Nacional de Alimentação Escolar PNAE, popularmente conhecido por merenda escolar.

O PNAE é gerenciado pelo Fundo Nacional de Desenvolvimento da Educação (FNDE) desde 1998. O objetivo do fundo de investimentos PNAE é colaborar para o desenvolvimento biopsicossocial, aprendizagem, rendimento escolar e a construção de hábitos alimentares saudáveis dos alunos. Todo esse processo é desenvolvido por ações de educação alimentar e nutricional, e pelas refeições nutritivas oferecidas aos estudantes. O FNDE é encarregado da transferência dos recursos do governo federal, em parceria com os estados, municípios e Distrito Federal para complementação dos recursos (Medeiro, 2013).

Os recursos designados à merenda escolar são repassados mensalmente, baseados no valor per capita e no censo escolar, assim os governos estaduais e federais são responsáveis por conduzir a verba repassada pelo FNDE, os municípios têm a liberdade para complementação de recursos na quantidade e melhoria do cardápio (Sales \& Fanego, 2018).

Estes recursos são transferidos para contas correntes específicas em 10 (dez) parcelas mensais, a partir do mês de fevereiro, para a cobertura de 200 (duzentos) dias letivos como designa o MEC, sem a necessidade de celebração de convênio, ajuste ou qualquer outro instrumento. Com o recebimento de recursos do governo federal é determinado que os municípios e as secretarias estaduais de educação devem prestar contas anualmente sobre os valores utilizados (Secretaria De Estado Da Educação De Goiás, 2012).

A prestação de contas destes recursos públicos é realizada através do demonstrativo com gastos feitos por uma entidade beneficiada em um determinado período. As escolas da rede municipal precisam realizar essa prestação até o mês fevereiro do ano subsequente ao do recebimento, apresentando formulários e documentos para comprovar a boa e regular aplicação dos recursos repassados (Sales \& Fanego, 2018). O coordenador de merenda realiza o demonstrativo de fluxo de caixa da escola e o entrega juntamente com as notas fiscais e as transferências ao secretário de educação, que envia a prestação de contas para o Sistema de Gestão de Prestação de Contas (SigPC). (Fundo Nacional de Desenvolvimento da Educação, 2017).

O fluxo de caixa é o registro de qualquer entrada ou saída de dinheiro do caixa da escola. Através da análise desse controle o coordenador de merenda verifica se as entradas estão maiores ou menores que as saídas, para tomar medidas de adequação do fluxo de caixa. (Passos, 2018).

A responsabilidade de administração de recursos repassados às escolas públicas, com finalidade de uso para a merenda escolar. Todo o controle como criação de cardápios e o controle de fluxo de caixa são realizados em planilhas eletrônicas, o que além de consumir um maior tempo de trabalho é mais suscetível a erros. (Weis, Belik \& Chaim, 2014). 
Os sistemas disponíveis possuem um alto custo, e não atendem a todas as necessidades relacionadas a gestão da merenda, dificultando a aquisição pelas escolas.

Por conta desses fatores, é relevante a criação de um sistema para gerenciamento de tais recursos pretendendo-se proporcionar mais facilidade no controle das verbas da merenda escolar, maior agilidade e eficiência.

Amorinópolis é uma pequena cidade, situada cerca de $25 \mathrm{~km}$ de Iporá-Go, estimasse-se que possui cerca de 3069 habitantes, de acordo com o último censo realizado em 2020 pelo Instituto Brasileiro de Geografia e Estatística (IBGE). (Instituto Brasileiro de Geografia e Estatística, 2020). A cidade de Iporá possui quatro instituições de ensino, sendo duas privadas e duas públicas, sendo uma delas o IF Goiano que em sua grade curricular oferece o curso de Analise e Desenvolvimento de Sistemas, que entre suas atividades de ensino, pesquisa e extensão procura atender e contribuir com o entorno onde é situado.

\section{Sistemas para Controle da Merenda Escolar - o Estado da Arte}

No mercado atual podem ser encontrados alguns softwares voltados ao gerenciamento da merenda escolar.

Foi feita uma análise de alguns sistemas com as funcionalidades que melhor atendiam as necessidades de uma escola de pequeno porte como é a atendida por esse projeto com cem alunos matriculados.

O Sistema de Alimentação Escola (SAESC), foi desenvolvido pela empresa BWI, com sede no Paraná. É um sistema pago que tem como propósito o acompanhamento das atividades e tarefas desenvolvidas pelas unidades e entidades executoras do PNAE, em nível municipal e/ou estadual, integradas aos demais programas de governos correlacionados. (BWI, 2015)

O SchoolMeals Web é desenvolvido por Teknisa Software com sede em Minas Gerais e realiza o planejamento da dieta escolar. Oferece a padronização de cardápio de acordo com cada tipo de ensino e necessidade nutricional de cada aluno. Também é um sistema pago. (Tekinisa Software, 2015).

Em 2015 foi desenvolvido um sistema Web por uma aluna do curso de Tecnologia em Análise e Desenvolvimento de Sistemas (TADS) do Instituto Federal Goiano - Campus Iporá para a mesma escola em questão. Com o nome de Controle de Merenda Escolar (CME) o software teve como objetivo geral informatizar o controle da merenda escolar. Oferecia funcionalidades como cadastro dos dados dos responsáveis pelas escolas, geração dos relatórios de produtos, cardápios, repasses e resumos das clientelas, necessários a prestação de contas deste controle, ao supervisor regional da merenda (Silva, 2015). O sistema não foi utilizado pelo fato de não ter sito testado ao ponto de receber aceitação e pelo surgimento de novas regras de negócio essências para melhor atender a escola.

Após analisar os softwares existentes no mercado, foi possível perceber alguns empecilhos para que sejam adotados por escolas públicas de pequeno porte. Os dois softwares estudados possuem, interface mais intuitiva e moderna. Porém, além de pagos, o SchoolMeals não realiza o controle financeiro, apenas o planejamento inteligente do cardápio e o SAESC realiza apenas a gestão dos gastos relacionados a merenda escolar.

A partir dessa análise, chegou-se à conclusão que seria melhor desenvolver um novo sistema em vez de uma manutenção perfectiva (Oliveira, 2017), pelo fato de a interface do CME estar obsoleta e a necessidade de remodelar e acrescentar funções ao sistema.

O novo sistema contará com o gerenciamento de recursos utilizados na merenda escolar, visando a necessidade de controle e registro das aquisições e gastos das verbas repassadas pelos governos federal e estadual, que devem ser destinadas exclusivamente a alimentação dos alunos.

Incluirá novas funcionalidades que irão além do controle de fluxo de caixa e passará por uma atualização da interface mais atual.

O software intitulado de Sistema de demonstrativo de fluxo de caixa da merenda escolar SDFCME oferecerá um 
aprimoramento na manipulação dos dados relacionados à merenda escolar, tendo como diferencial relatórios do demonstrativo de fluxo de caixa, sugestões de cardápios com os produtos disponíveis, avisos de produtos com data de validade mais antiga. Em cumprimento da lei n ${ }^{\circ} 11.947$, de 16 de junho de 2009 Art. 14. Que define que:

Do total dos recursos financeiros repassados pelo FNDE, no âmbito do PNAE, no mínimo 30\% (trinta por cento) deverão ser utilizados na aquisição de gêneros alimentícios diretamente da agricultura familiar e do empreendedor familiar rural ou de suas organizações, priorizando-se os assentamentos da reforma agrária, as comunidades tradicionais indígenas e comunidades quilombolas. (lei nº 11.947,2009).

Espera-se que o sistema desenvolvido possa contribuir com a minimização de falhas e melhor aproveitamento dos recursos destinados à merenda escolar.

\section{Material e Métodos}

Para o desenvolvimento optou-se por uma aplicação Web, pelo seu fácil acesso. Segundo Miletto e Bertagnoli (2014) os softwares desenvolvidos para a plataforma Web, são incorporados de forma que possam ser acessados remotamente e seguros por meio de um navegador. Ao optar por um sistema Web, cria-se a possibilidade e facilita na utilização por outras escolas municipais de Amorinópolis.

Segundo Niederauer (2017) o Hypertext Preprocessor (PHP) por ser uma linguagem de programação popular que traz boas características como ser gratuito, ser embutido no HyperText Markup Language (HTML) e suporta diversos tipos de banco de dados.

Foi utilizada linguagem de programação JavaScript, linguagem de marcação HTML, folhas de estilo Cascading Style Sheets (CSS), além do framework front-end Materialize, para o design do software. Para auxiliar na programação foi utilizado o ambiente de desenvolvimento integrado (IDE) Atom, por ser multiplataforma e gratuito. (Negromonte, 2016).

Para o gerenciamento do banco dados foi utilizado o Sistema Gerenciador de Banco de Dados (SGBD) MySQL, por se destacar nos recursos de consulta ao banco de dados, possuir meios para definição da estrutura de dados, modificação de dados e especificação de segurança. (Nascimento, 2015).

Para a elicitação de requisitos foram escolhidas as técnicas de estudo de documentos e entrevistas com questões abertas, por ser constantemente aplicada em pesquisa qualitativa que em geral, decorre no ambiente natural com coleta objetiva de informações e o pesquisador é o principal instrumento. (Pereira. et al.,2018). Foi utilizada a metodologia de entrevista aberta comumente utilizada para especificar conceitos abordados, e por ser um tipo mais flexível. (Batista; Matos \& Nascimento, 2017). Segundo Pereira et al. (2018), pode-se definir método qualitativo como "aqueles nos quais é importante a interpretação por parte do pesquisador com suas opiniões sobre o fenômeno em estudo". O estudo de documentos possibilita acrescentar o entendimento de itens, cuja compreensão necessita de contextualização histórica e sociocultural. (Sá-Silva \& Guindani, 2009).

O modelo de processo utilizado foi a cascata revisto, por ser um método linear e sequencial, este modelo prevê a possibilidade, a partir de qualquer etapa do ciclo, viabilizar o retorno a etapa anterior. Através do cascata revisto, será realizado o controle e planejamento, para cada estágio de desenvolvimento (Lessa \& Lessa Junior, 2009). O modelo de desenvolvimento foi escolhido devido a entrega do produto de desenvolvimento de software ser entregue após sua total conclusão. 


\section{Resultados e Discussões}

\section{Escopo}

O software tem como finalidade realizar o controle com gastos de entrada e saída relacionados a compras de produtos para a merenda escolar, proporcionando uma prestação de contas com maior exatidão, e facilidade aos responsáveis, auxiliar no desenvolvimento dos cardápios, controle de estoque dos produtos e gerar relatórios.

O software conta com módulos que auxiliam o secretário de educação no cadastro da escola, como o cadastrado coordenador de merenda. Além disso, o secretário de educação deve cadastrar os órgãos públicos que fornecem verbas para a merenda, e o cadastro das clientelas que são as modalidades de ensino contempladas com a merenda escolar.

Os módulos referentes ao controle prestado pelo coordenador de merenda permitem o cadastro de fornecedores, o cadastro de produtos, notas fiscais e aviso de crédito (repasse) realizado pelo governo estadual e federal, podendo ser complementado com verba municipal.

\section{Diagrama de caso de Uso Geral}

Para o desenvolvimento do software é necessário determinar quem serão os usuários do sistema (Ator), e como eles irão utilizá-lo, para esse fim usa-se da técnica chamada Caso de Uso, que possibilita identificar os requisitos do sistema através do seu uso. (Guedes, 2011).

A Figura 1 ilustra o diagrama de caso de uso, que foi desenvolvido para melhor entendimento das partes envolvidas no sistema, apresentando as funções externamente visíveis que o software proporciona no contexto de seu ambiente, apresentando as funcionalidades do sistema, e o relacionamento entre elas.

Figura 1. Diagrama caso de uso geral.

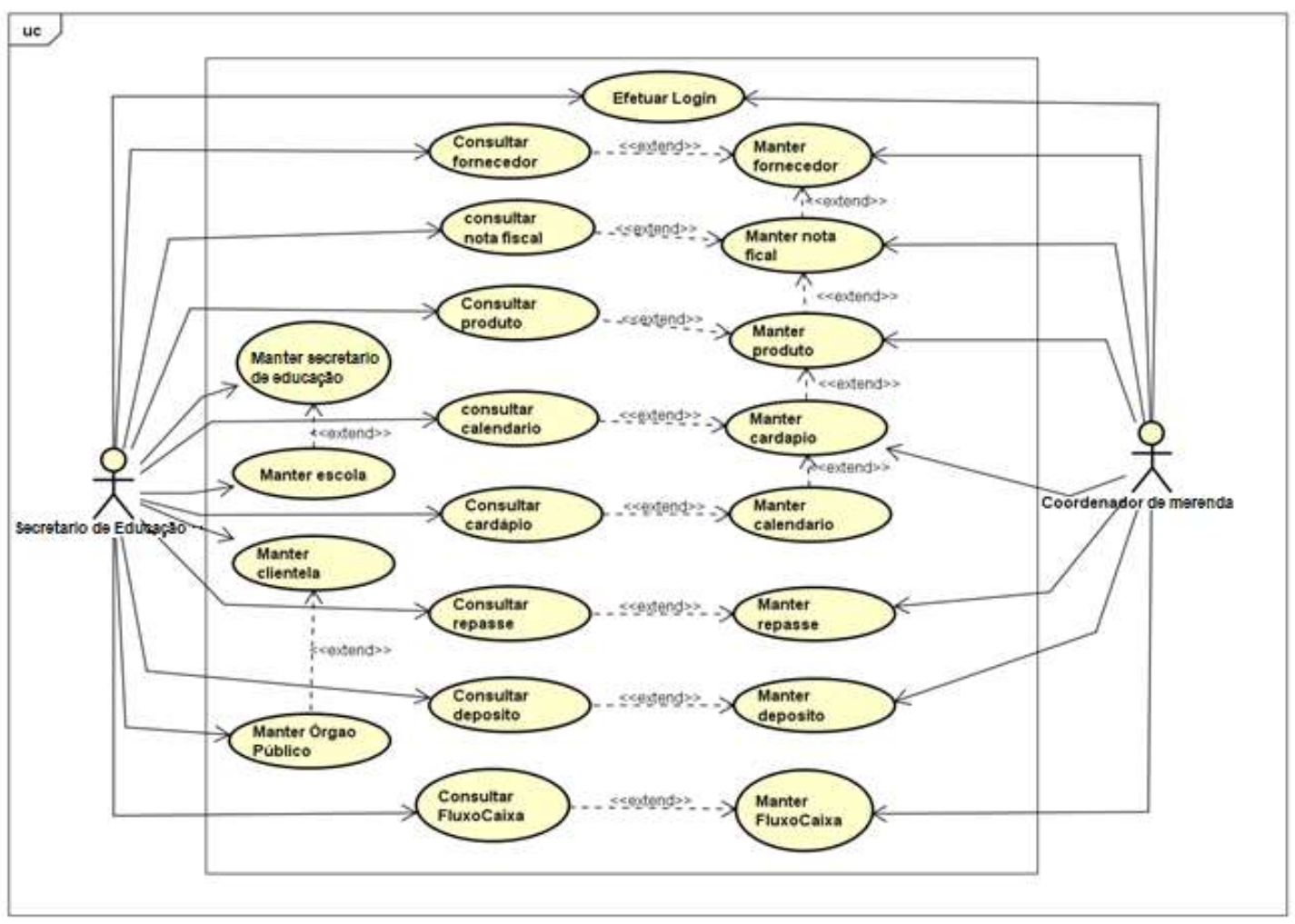

Fonte: Autores (2020). 
A Figura 1 representa o diagrama de caso de uso geral, com uma visão das principais funcionalidades do sistema, onde é possível visualizar as ações dos atores que são secretário de educação e o gerente de merenda, sendo o secretario o responsável por manter os dados de outros secretários, escolas, clientelas e órgãos públicos, além disso, o secretário de educação e capaz de consultar os dados de fornecedores, notas fiscais, produtos, cardápios, calendários, repasses, deposito e fluxo de caixa, e gerar relatórios de produtos utilizados, cardápios lançados e fluxo de caixa. Já o gerente de merenda terá permissão de manter os dados de fornecedores, produtos, notas fiscais, cardápios, calendários, repasses, deposito e fluxo de caixa.

\section{Tela inicial do Sistema}

A Figura 2 representa a tela inicial do sistema, nela é possível realizar o login, onde o usuário seja o secretário de educação ou coordenador de merenda inserem seus dados para acessar o sistema.

Nessa tela estão disponíveis as funcionalidades relacionadas ao ator secretário de educação, tais como: o cadastro de um novo secretário de educação, escola, clientela e órgão público e consultar fornecedor, nota fiscal, produto, cardápio, calendário, aviso de credito e fluxo de caixa.

Figura 2. Tela do Secretário de Educação.

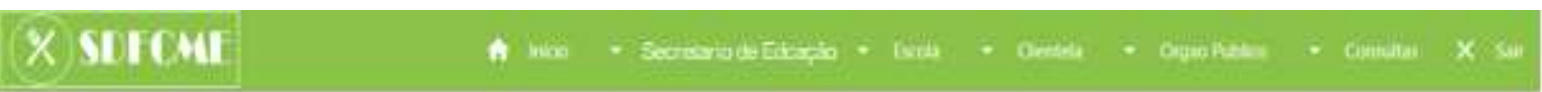

\section{Sisfema the Leancnsfrative fe I Ims de Caisa La Merenda Iscrlar}

Fonte: Autores (2020).

Conforme ilustra a Figura 2 para uma escola utilizar o sistema o secretario de educação deve cadastrar a escola, inserindo os dados necessários, após isso deve cadastrar a clientela que é a modalidades de ensino. Ex: ensino médio, ensino fundamental, cadastrar o órgão publico que fornecem verbas Federais e Estaduais e a função de consulta, onde o secretario pode fiscalizar as ações da escola.

\section{Tela do Coordenador de Merenda}

A Figura 3 representa a tela inicial do coordenador de merenda onde após o secretário de educação cadastrar a escola, o coordenador de merenda pode acessar a pagina destinada a escola e realizar os cadastros necessários para o gerar o relatório de fluxo de caixa. 
Figura 3. Tela do Coordenador de merenda.

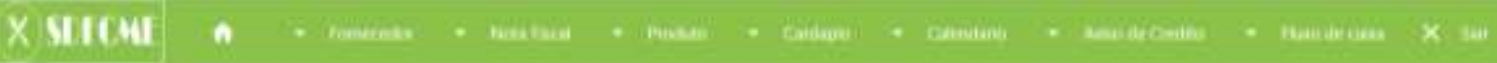

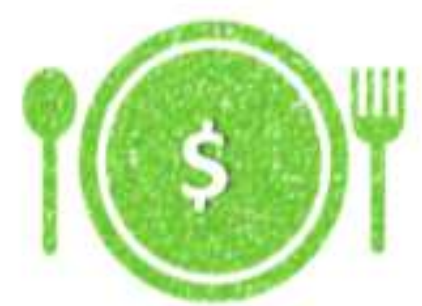

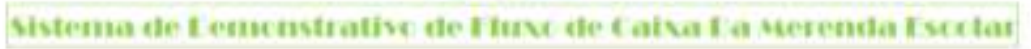

Fonte: Autores (2020).

Conforme ilustra a Figura 3, na tela de acesso da escola estão disponíveis as funcionalidades relacionadas ao ator coordenador de merenda, que tem por função, cadastro de fornecedores da escola, cadastrar nota fiscal das compras realizadas, cadastrar nome e quantidade do produto , cadastrar cardápio da semana, cadastrar o calendário com a clientela e o cardápio, cadastrar o aviso de credito com o valor da verba recebida pelo Governo estatual e federal e por fim gerar os relatórios de fluxo de caixa quando necessário.

\section{Tela cadastrar escola}

A Figura 4 representa a tela de cadastro dos dados da escola, onde o coordenador de merenda é o único autorizado a cadastrar novas escolas. Apenas depois do cadastro da escola o gerente de merenda tem acesso ao sistema.

Figura 4. Tela Cadastrar Escola.
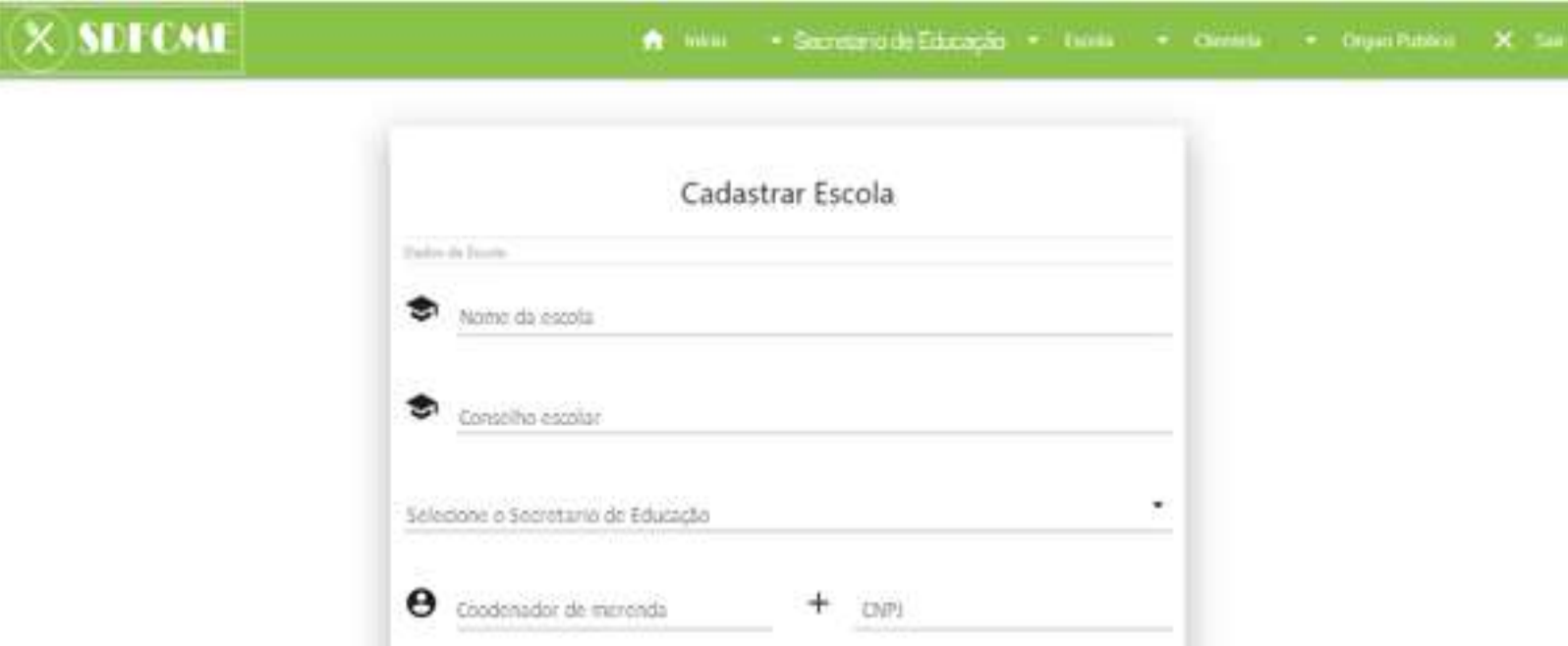

Fonte: Autores (2020). 
É possível visualizar na Figura 4 a tela de cadastro de uma escola, nesta página o secretário educação deve cadastrar a escola inserindo nome, conselho escolar, CNPJ, subsecretaria, telefone, coordenador de merenda, e-mail do coordenador administrativo e endereço.

\section{Diagramas de Classe}

O diagrama de classes a seguir descreve as classes do sistema e os atributos necessários a cada classe, assim como suas respectivas funções. Baseados em orientação a objeto os relacionamentos entre as classes garantem a comunicação entre os objetos (Guedes, 2011). A Figura 11 retrata as classes do sistema com seus respectivos relacionamentos.

Figura 5. Diagramas de classe.

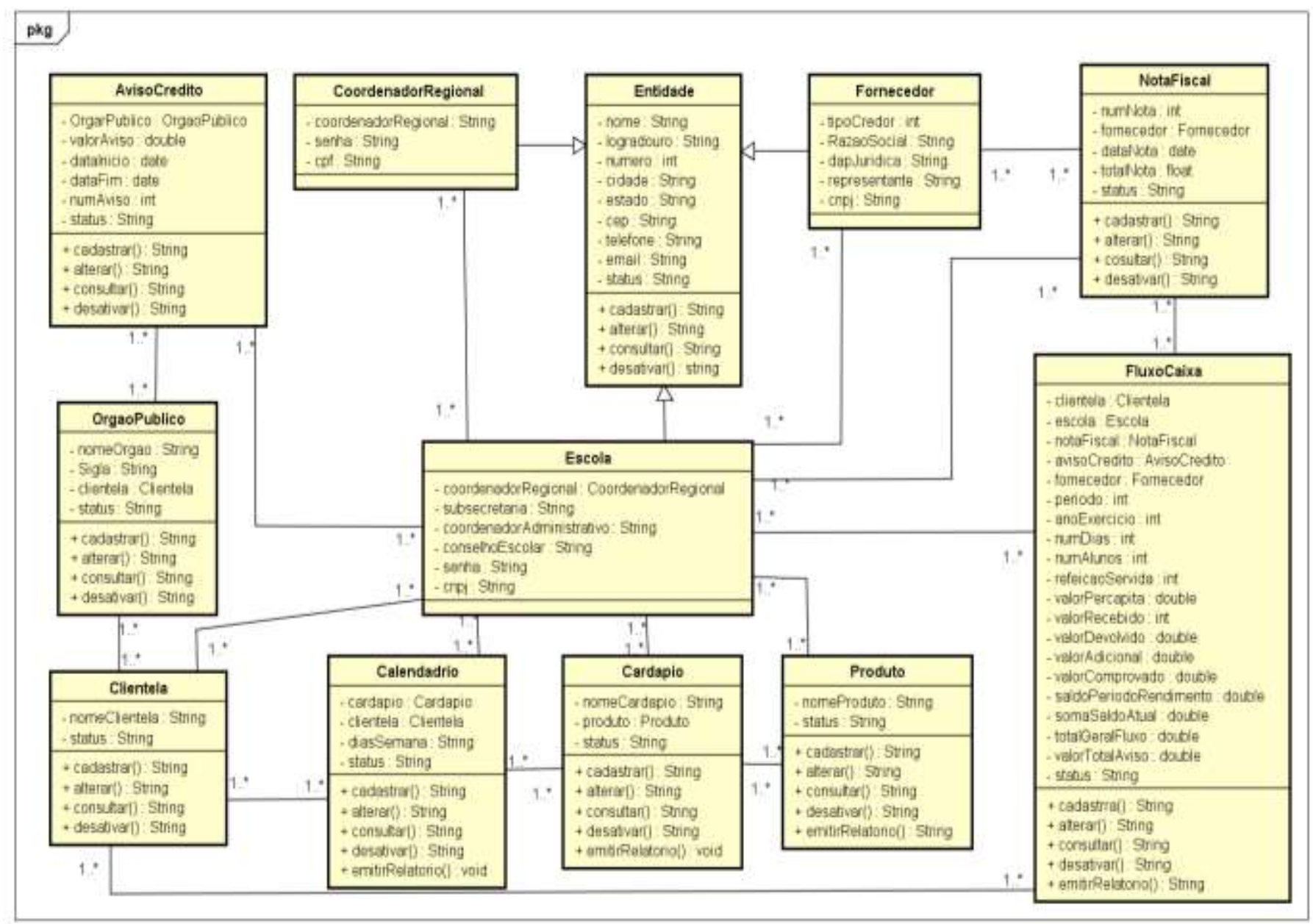

Fonte: Autores (2020).

O diagrama de classe ilustrado pela Figura 5 possibilita a visualização das classes que formam o sistema, representando do mesmo modo os métodos e atributos das classes.

\section{Arquitetura do sistema}

O sistema foi desenvolvido através da arquitetura MVC (model, view, controller), a fim de dividi-lo em camadas, onde a camada model é responsável por armazenar dados que serão implementados em outras páginas, a camada view é a 
responsável por armazenar os dados relacionados à interface do sistema, e na camada controller são executadas ações que definem como as interfaces devem agir a partir dos dados inseridos pelos usuários. (Rocha, 2018).

Figura 6. Arquitetura do Sistema.

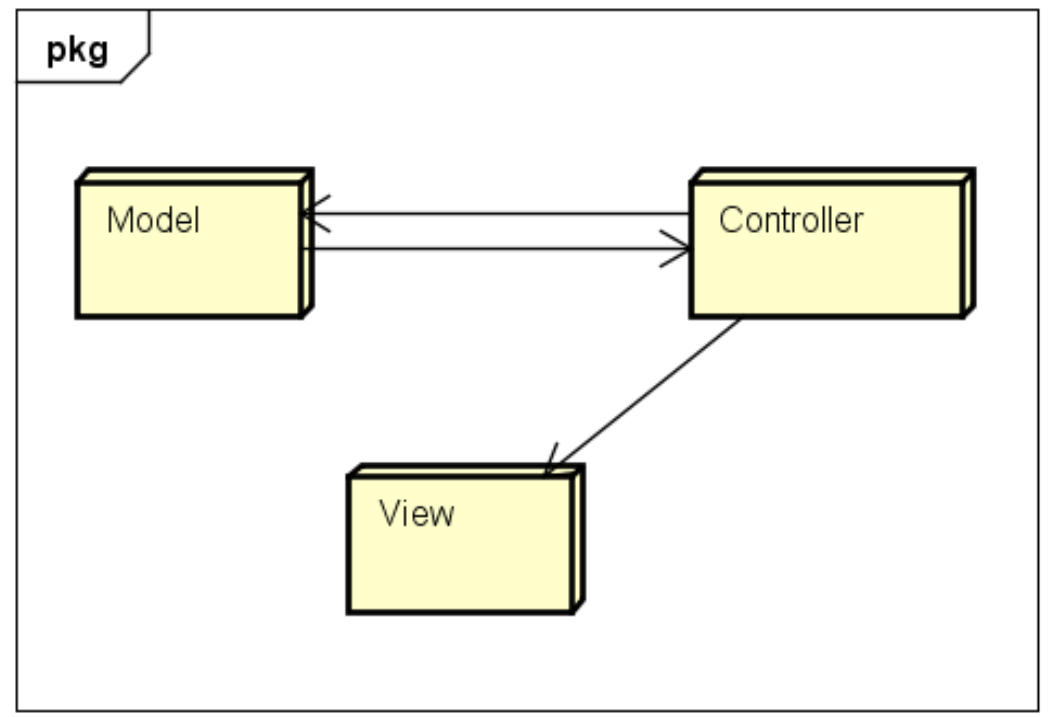

Fonte: Autores (2020).

A Figura 6 ilustra as o relacionamento das tabelas, onde é possível visualizar as comunicações da model com o controller para processar operações de busca ou armazenamento, e por fim o controller delega para a view gerar um resultado.

\section{Considerações Finais}

A merenda escolar é uma refeição oferecida aos alunos de escolas da rede pública desde meados de 1940, é custeada pelo Governo Federal através do PNAE.O objetivo dessa verba é contribuir para o desenvolvimento integral dos alunos e consequentemente colaborar com sua aprendizagem.

E necessário prestar contas dos valores recebidos pelo Governo Federal, porem atualmente em escolas públicas esse controle e realizado manualmente, o que muitas vezes demanda uma grande quantidade de tempo, esforços e é suscetível a erros.

Os sistemas disponíveis no mercado não atendem o perfil de escolas públicas de pequeno porte, além de não serem gratuitos, inviabilizando a aquisição por parte das escolas.

A modelagem do sistema decorre da problemática identificada em uma escola do município de Amorinópolis-GO. Durante o desenvolvimento do projeto, foi necessário o entendimento de como ocorre a prestação de contas, pois a escola realiza o controle de fluxo de caixa e cardápio manualmente e com auxílio de planilha eletrônica.

O objetivo do estudo foi atingido, por meio da apresentação do controle relacionado a merenda escolar, tendo como resultado final a modelagem de um sistema capaz de auxiliar no controle de fluxo de caixa da merenda escolar.

Como trabalhos futuros, propõe-se a melhoria no cadastro das notas fiscais, para que seja possível, após o seu o preenchimento, a importação de um arquivo XML gerado pelos fornecedores, além disso a conclusão do módulo de fluxo de caixa, e implementação de uma função que permita ao selecionar os alimentos para a criação de um cardápio, seja possível visualizar a quantidade ideal de alimentos a ser feita para um número x de alunos. 


\section{Referências}

Batista, E. C., Matos, L. A. L., \& Nascimento, A. B. (2017) A entrevista como técnica de investigação na pesquisa qualitativa. Revista Interdisciplinar Científica Aplicada, Blumenau. https://rica.unibes.com.br/rica/article/download/768/666

BWI, (2015). Sistema de Alimentação Escolar. Paraná, https://www.alimentacaoescolar.com/sobre-nos/

Chaves, L. G., \& Brito, R. R. D. (2006). Políticas de Alimentação Escolar-Brasília: Centro de Educação a Distância (CEAD), Pro-funcionário, Curso Técnico de Formação para os Funcionários da Educação. Universidade de Brasília.http://portal.mec.gov.br/seb/arquivos/pdf/profunc/12_pol_aliment_escol.pdf

Decreto $n^{o}$ 37.106, de 31 de março de 1955. Institui a companha da Merenda Escolar. Página 465. https://www2.camara.leg.br/legin/fed/decret/19501959/decreto-37106-31-marco-1955-332702-publicacaooriginal-1-pe.html

Fundo Nacional de Desenvolvimento da Educação. (2017). Prestação de contas. https://www.fnde.gov.br/programas/pnae/pnae-prestacao-de-contas

Guedes, G. T. A. (2011). UML2: uma abordagem prática. Novatec Editora.

Instituto Brasileiro de Geografia e Estatística. (2020). População no último censo. https://cidades.ibge.gov.br/brasil/go/amorinopolis/panorama

Lei $n^{o}$ 11.947, de 16 de junho de 2009. Art. 14. Dispõe sobre o atendimento da alimentação escolar e do Programa Dinheiro Direto na Escola aos alunos da educação básica; altera as Leis nos 10.880, de 9 de junho de 2004, 11.273, de 6 de fevereiro de 2006, 11.507, de 20 de julho de 2007; revoga dispositivos da Medida Provisória no 2.178-36, de 24 de agosto de 2001, e a Lei no 8.913, de 12 de julho de 1994 ; e dá outras providências. Brasil. http://www.planalto.gov.br/ccivil_03/_ato2007-2010/2009/lei/111947.htm

Lessa, R. O., \& Lessa Júnior, E. O. (2009). Modelos de Processos de Engenharia de Software. Universidade do Sul de Santa Catarina. http://xps-project. googlecode.com/svn-history/r43/trunk/outros/02_Artigo. pdf.

Medeiro, L. G. C. (2013) Políticas de Alimentação Escolar. Cuiabá-MT. http://tinyurl.com/y4xgaq9g.

Miletto, E. M., \& Bertagnoli, S. C. (2014) Desenvolvimento de software II: Introdução ao desenvolvimento Web com HTML, CSS, JavaScrip e PHP. Porto Alegre: Bookman. http://tinyurl.com/y27628ny.

Nascimento, B. S. (2015). MySQL Tutorial. https://www.devmedia.com.br/mysql-tutorial/33309.

Negromonte, E. (2016). Atom - seu próximo IDE. https://sempreupdate.com.br/atom-seu-proximo-ide/.

Niederauer, J. (2017). Desenvolvendo websites com PHP: aprenda a criar Websites dinâmicos e interativos com PHP e bancos de dados $3^{\text {a }}$ Edição. São Paulo. Novatec Editora.

Oliveira, J. C. A. D. (2017). Refatoração estrutural da base de dados do módulo Gestão RH do sistema SIAF-UFU. https://repositorio.ufu.br/handle/123456789/25267

Passos, E, N.(2018) Gestão financeira: verificação da adequação do plano de curso frente às necessidades e carências dos alunos da Escola Aprender. http://tinyurl.com/y4637mgn

Ramos, L. S., Moreira, E. M. F., da Silva, F. A., Nazário, E. A. M., Sobrinho, L. R. P., do Nascimento Brito, D., \& de Almeida, E. M. (2020). A humanização da merenda escolar na promoção da saúde e da educação pública: Uma breve revisão. Revista Eletrônica Acervo Saúde, (44), e3137-e3137. DOI https://doi.org/10.25248/reas.e3137.2020

Rocha, J. G. (2018). Arquitetura em Camadas com uso do Paradigma MVC e Processo Unificado na Programação de Software Orientado a Objetos. Tecnologias em Projeção, 9(1), 31-49. http://revista.faculdadeprojecao.edu.br/index.php/Projecao4/article/view/1068

Sá-Silva, J. R., de Almeida, C. D., \& Guindani, J. F. (2009). Pesquisa documental: pistas teóricas e metodológicas. Revista brasileira de história \& ciências sociais, 1(1). https://www.rbhcs.com/rbhcs/article/viewFile/6/pdf.

Sales, R. M. L. A., \& Fanego, G. (2018). Fiscalização dos Recursos da Merenda Escolar nas Escolas Públicas do Município de Satuba em Alagoas, desde o início até 2016. ID on line Revista De Psicologia, 12(41), 937-960. DOI: https://doi.org/10.14295/idonline.v12i41.1272

Secretaria De Estado Da Educação De Goiás.(2018). Manual de Orientação para a Execução do Programa Nacional de Alimentação Escolar de Goiás. Goiânia. http://tinyurl.com/y4637mgn.

Silva, J. L. (2015). Projeto e desenvolvimento de um sistema web para controle de merenda escolar nas escolas em goiás.

Tekinisa Software. (2015). SchoolMeals. Tekinisa Software. https://www. tekinisa.com/produtos/schoolmeals-alimentacao-escolar.

Weis, B., Belik, W., \& Chaim, N. A. (2014). Manual De Gestão Eficiente Da Merenda Escolar. $1^{\circ}$ Edição. http://www.seduc.go.gov.br/documentos/ merenda/Manual\%20-\%20Merenda\%20Escolar.pdf 